\title{
The effect of notch size on fatigue crack threshold and propagation in cast gamma titanium aluminide
}

\author{
Claire Trant ${ }^{1}$, Nigel Martin ${ }^{2}$, Mark Dixon ${ }^{2}$, Edward Saunders $^{3}$, Trevor Lindley ${ }^{1}$, David Dye ${ }^{1}$ \\ 1 Department of Materials, Imperial College London
}

2 Rolls-Royce plc., Materials, Elton Road, Derby DE24 8BJ, UK

3 Rolls-Royce plc., Materials-Failure Investigation, Bristol, BS 34 7QE, UK

\begin{abstract}
Cracks were initiated and grown from notched specimens with notch lengths of 0.03 (FIB), 0.06, 0.1 and $0.5 \mathrm{~mm}$ (diamond blade), in cast gamma titanium aluminide at $400{ }^{\circ} \mathrm{C}$. Specimens with longer 0.1 and $0.5 \mathrm{~mm}$ notches initiated from the notch and show no effect from initial notch size on either crack growth threshold or propagation. Specimens with shorter 0.03 and $0.06 \mathrm{~mm}$ notches initiated naturally, cracking from microstructural features away from the notch. The fracture surfaces of these specimens were characterised to distinguish areas of initiation, fatigue and overload. Multiple initiation sites were observed on these fracture surfaces. It is inferred that, for this alloy and process route, microstructural initiation is dominant where notches are less than $\sim 100 \mu \mathrm{m}$ in size.
\end{abstract}

Introduction

Gamma titanium aluminide ( $\gamma$-TiAl) based alloys have long been attractive for use in jet engines due to their low density, around $4 \mathrm{gcm}^{-3}$, strength, oxidation resistance, and creep resistance at intermediate temperatures in the range of $450-700{ }^{\circ} \mathrm{C}$ [1]. This has prompted development efforts stretching back as far as 1953 [2], but only recently have this class of alloys begun to see service in civil jet engines.

The limited ductility and relatively fast crack propagation of $\gamma$-TiAl make its use as a material for highly stressed components particularly challenging. The fatigue crack growth threshold has been identified as a key material property for design, supported by an improved understanding of the deformation mechanisms associated with a crack growing near this threshold.

Investigation into fatigue crack growth, and therefore life determination, falls into two main categories: lifing prior to any defect, or defect tolerant approaches [3]. Defect tolerant approaches assume that a defect either existed in the material, or is introduced for the investigation of crack growth. For small initial defects, less than the plastic zone size, it is interesting to ask whether the initiating defect may affect the crack growth threshold. Many other factors also affect the stress intensity at which a crack initiates, including temperature, local microstructure such as crystallographic orientation or initiating microstructural features, or any effect of environment on the crack, such as oxidation-induced closure [4][5].

The rate of crack growth, da/dN, is not only affected by the instantaneous stress intensity $(\Delta \mathrm{K})$ but may also be affected by the initial crack size. There is also the observation that small cracks, defined as those smaller than a few millimetres in length, often show crack growth rates much faster than those in longer cracks when the same $\Delta \mathrm{K}$ is applied. Furthermore, cracks that are similar size to the microstructure exhibit a rate of crack growth which diminishes with an increase in crack length [3]. The critical flaw size in $\gamma$-TiAl is typically small, and its further investigation is crucial to design [6].
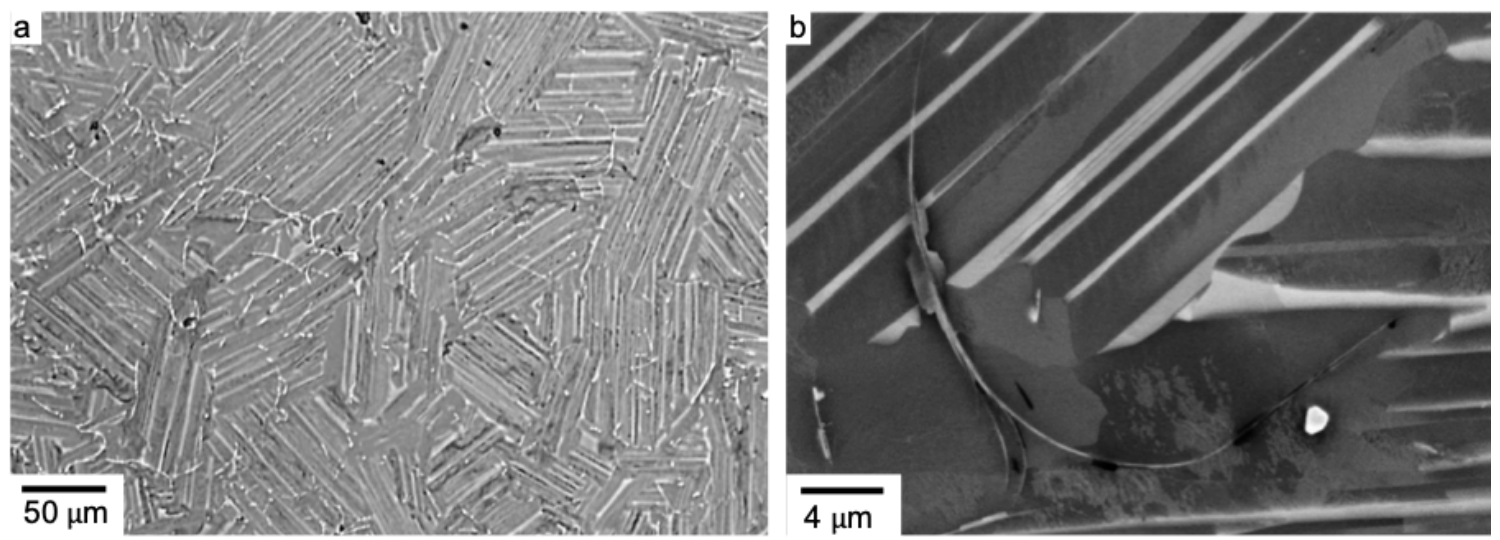

Figure 1: a) An optical micrograph of the microstructure of the cast as-received $\gamma$-TiAl showing the coarse lamellar microstructure of $\gamma$ (darker) and $\alpha_{2}$ (lighter), and the colony size in the range of $40-100 \mu \mathrm{m}, \mathrm{b}$ ) scanning electron micrograph (backscatter mode) of a curved boride, $\mathrm{TiB}_{2}$. 


\section{Experimental Procedures}

The $\gamma$-TiAl alloy studied was cast and underwent hot isostatic pressing (HIP) to reduce porosity. For microstructural characterisation, a metallographic sample was prepared using standard procedures, then polished with neutralised colloidal silica (70 ml colloidal silica, $30 \mathrm{ml} \mathrm{H} \mathrm{O}_{2}$ and $100 \mathrm{ml} \mathrm{H}_{2} \mathrm{O}$ ) and etched using Kroll's reagent $(2 \mathrm{ml} \mathrm{HF}, 6 \mathrm{ml}$ $\mathrm{HNO}_{3}$, balance $\mathrm{H}_{2} \mathrm{O}$ ) to expose the microstructure shown in Figure 1a. The microstructure consists of prior $-\beta$ grains, with boron added as $\mathrm{TiB}_{2}$, as a grain refiner. This is found at the colony boundaries, also less frequently within colonies as ribbons, Figure $1 \mathrm{~b}$. Within the prior ${ }^{\beta}$ grains randomly oriented colonies of $\gamma$-TiAl and $\alpha_{2}-\mathrm{Ti}_{3} \mathrm{Al}$ were obtained, $40-100 \mu \mathrm{m}$ in size, consisting of $92 \%$ area fraction of $\gamma$-TiAl lamellae. In Figure 1, $\gamma$ is darker in colour and 2 - $7 \mu \mathrm{m}$ in lath width, often with several laths together. The $\gamma$ is interleaved with thin ligaments of $\alpha_{2}$, lighter in colour, $0.2-0.7 \mu \mathrm{m}$ in plate width [7].

Cast bars were machined to form M12 threaded, 5 x $5 \mathrm{~mm}$ square section specimens with a gauge length of $15 \mathrm{~mm}$ and a machined corner notch. The specimen gauge lengths were then hand polished using neutralised colloidal silica. In the corner crack specimens, notches were created in the central $1 \mathrm{~mm}$ region of the gauge. The following notch sizes were machined by diamond saw: $0.5,0.1$ (Figure 2a) and $0.06 \mathrm{~mm}$. The shape of the as machined notches can be seen to form a $\mathrm{U}$ shape, with a crack notch radius of $\sim 50 \mu \mathrm{m}$. This was considered to be a sharp notch [8][9]. Notches that were smaller than this were made using a gallium Focussed Ion Beam (FIB) on FEI Helios Nanolab 600 DualBeam system, as can be seen in Figure $2 \mathrm{~b}$. The FIB notch was created to try to replicate the geometry of the machined notches. However, the shape of the notch created using the Ga FIB can be seen to form a sharper V shape, with the crack notch radius only measuring a few microns. This must be taken into consideration when the influences of crack size on the stress intensity threshold is investigated. Ga FIB can also be seen to deposit Ga in the sample when milling. When the FIB notch is created using the Ga ion beam, the geometry was taken into consideration in order to minimise the elemental gallium traces deposited in the specimen, Figure 2c, as it is thought that Ga deposition in the notch may have an effect on the results of the study of the influence of notch size on stress intensity threshold during fatigue testing.
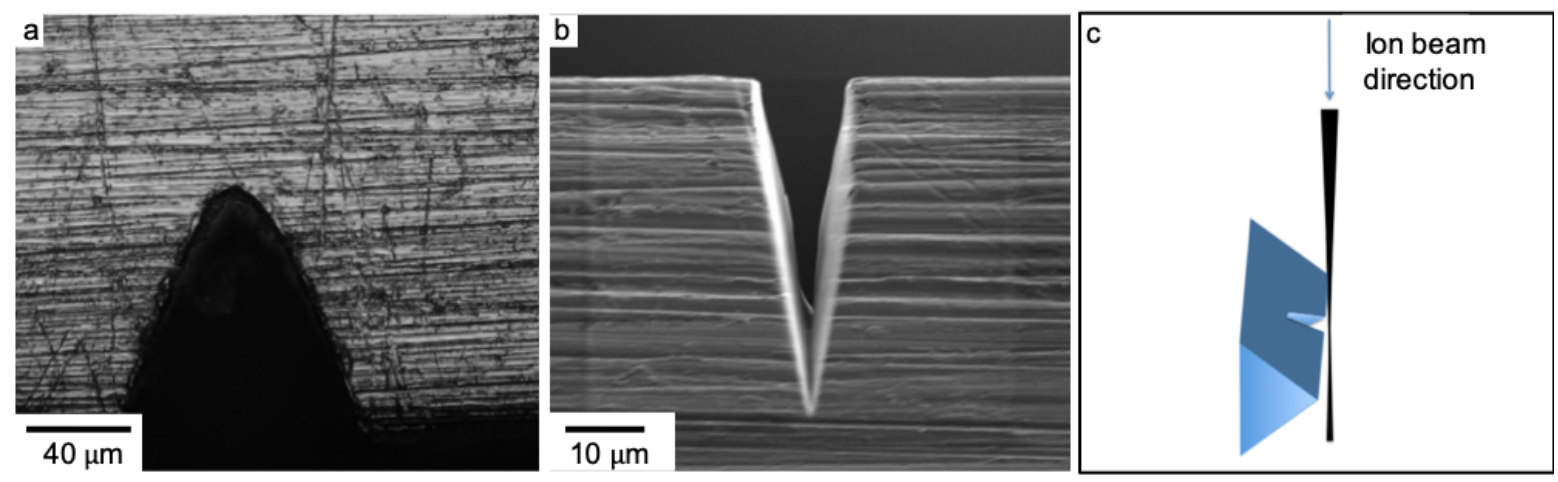

Figure 2: a) $0.1 \mathrm{~mm}$ notch machined by diamond saw, b) $0.03 \mathrm{~mm}$ notch milled by Ga FIB, c) schematic of the geometry used to FIB $0.03 \mathrm{~mm}$ notch to minimise Ga deposition.

Indirect crack growth measurement was carried out using the direct current potential drop (DCPD) technique using a Matelect DCM-2. The loading waveform was sinusoidal, $\mathrm{R}=0.1$, at a frequency of $5 \mathrm{~Hz}$ using a servo hydraulic 100 $\mathrm{kN}$ Mayes frame with an Instron 8800 controller. Measuring fatigue crack growth of small cracks used 2 x $0.063 \mathrm{~mm}$ diameter Pt probes spot welded either side of the notch in the corner crack specimen. The corner crack specimen was inserted and load stabilised at $1 \mathrm{kN}$, the temperature was then increased and stabilised at $400{ }^{\circ} \mathrm{C}$. Threshold was determined using small nominal incremental increases in stress intensity until a crack growth rate of $10^{-10} \mathrm{~m} /$ cycle was observed. The standard method using pre-sharpening of the starter notch could not be used due to the high fatigue crack growth rates typically found in this class of material.

\section{Results}

The fatigue crack growth curve for 0.1 and $0.5 \mathrm{~mm}$ notches is shown in Figure 3. The crack growth threshold for both was found to be approximately $4 \mathrm{MPa} \sqrt{\mathrm{m}}$. Crack growth propagation was also found to be similar for both, in the central Paris regime. Crack growth threshold was measured for nine specimens with a $0.5 \mathrm{~mm}$ machined starter notch, averaging at $4.04 \mathrm{MPa} \sqrt{ } \mathrm{m}$ with a standard deviation of $0.14 \mathrm{MPa} \sqrt{ }$. Crack growth threshold was measured for two specimens with a $0.1 \mathrm{~mm}$ machined starter notch, measuring 4.1 and $4.9 \mathrm{MPa} \vee \mathrm{m}$. Due to the crack growth threshold being so repeatable, the large value for the threshold of the $0.1 \mathrm{~mm}$ notch can be discounted, although it might be expected to be slightly more variable for a smaller notch consequently interacting with fewer colonies. The threshold 
for both the 0.1 and $0.5 \mathrm{~mm}$ notch is therefore similar, at around $4 \mathrm{MPa} \sqrt{\mathrm{m}}$. The gradient of the $\mathrm{da} / \mathrm{dN}$ curve for a 0.5 $\mathrm{mm}$ starter notch was measured in four specimens, measuring $3.9 \sqrt{\mathrm{m}} / \mathrm{MPa} /$ cycle with standard deviation of 0.5 $\sqrt{\mathrm{m}} / \mathrm{MPa} /$ cycle at $\Delta \mathrm{K}>11 \mathrm{MPa} \sqrt{\mathrm{m}}$. The gradient of the da/dN curve for a $0.1 \mathrm{~mm}$ starter notch was measured in two specimens, measuring 6.8 and $6.3 \sqrt{\mathrm{m}} / \mathrm{MPa} /$ cycle. The crack propagation rate for the 0.1 and $0.5 \mathrm{~mm}$ notches were therefore similar, but found to be slightly higher at the higher stresses associated with the higher stress required for the smaller notch sizes.

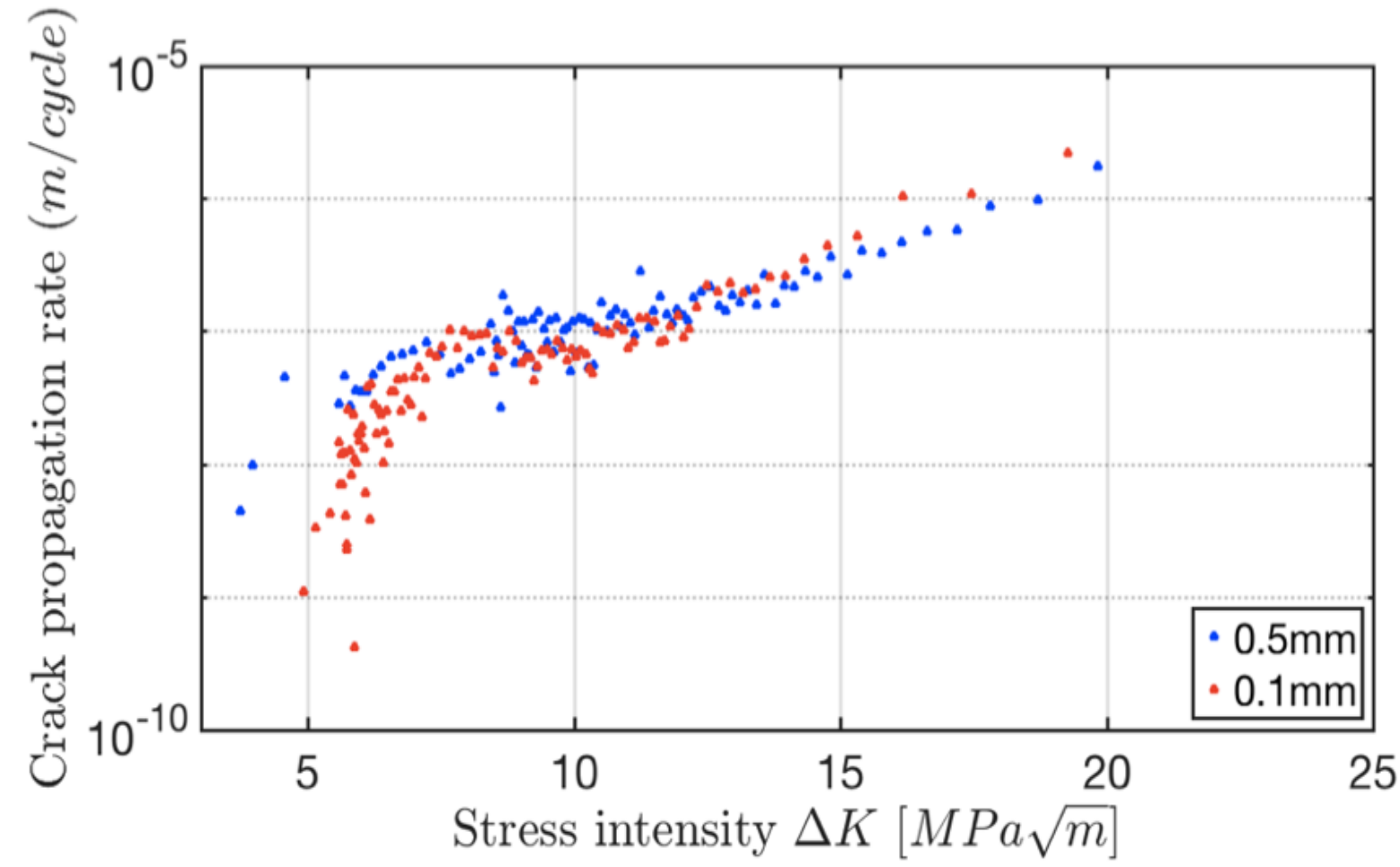

Figure 3: A stress intensity plot of the $0.5 \mathrm{~mm}$ and $0.1 \mathrm{~mm}$ notches from initiation to failure. Both the $0.5 \mathrm{~mm}$ and $0.1 \mathrm{~mm}$ notch were observed to have a threshold of approximately $4 \mathrm{MPa} \sqrt{\mathrm{m}}$ and a similar crack growth rate.

Figure 4a shows the fracture surface of $0.5 \mathrm{~mm}$ notched corner crack specimen at $400{ }^{\circ} \mathrm{C}$, with the notch visible in the bottom left corner. The crack propagated in fatigue from this notch, initially in trans-lamellar crack growth, therefore with limited roughness, Figure 4b. The crack continued in this mode of growth for approximately $2 \mathrm{~mm}$. The fracture surface then showed an increased roughness with crack growth modes being predominantly inter- and intra-lamellar, Figure $4 \mathrm{c}$, until failure at the top right of the fracture surface. This change in crack growth mode can be hard to observe optically but can be discerned by careful observation in the SEM, accompanied by optical surface profilometry.

Plastic zone size, $r_{p}$, can be determined by Equation 1, where $K$ is stress intensity and $\sigma_{y}$ is the yield stress, $450 \mathrm{MPa}$ for $\gamma$-TiAl at $400{ }^{\circ} \mathrm{C}$. In Figure 4 we can see that fatigue crack growth occurs in the interval between $4 \mathrm{MPa} \sqrt{\mathrm{m}}$ at threshold, to final failure at around $20 \mathrm{MPa} \sqrt{\mathrm{m}}$. This gives a plastic zone size range from tens of microns, to hundreds of microns. The average colony size was found to be $40-100 \mu \mathrm{m}$. The plastic zone size coincides with this size between stress intensity values of $9-11 \mathrm{MPa} \sqrt{\mathrm{m}}$, or a crack length of $1.9-2.3 \mathrm{~mm}$. This coincides with the change in the crack growth from trans-lamellar to inter- and intra-lamellar crack growth in Figure 4, at approximately $2 \mathrm{~mm}$.

$r_{p}=\frac{K^{2}}{2 \pi \sigma_{y}^{2}}$

Equation 1

Notches smaller than the colony size initiated naturally, away from the notch, at microstructural features, such as favourably oriented grains. From the area of initiation, crack growth in fatigue was observed to be trans-lamellar, due to the plastic zone size being less than that of a colony, providing a flatter surface. With an increase in crack length, the stress intensity increases. Once this increased the plastic zone size to larger than the colony size, an increase in surface roughness could be observed, coinciding with a change in fracture mode to inter- and intra-lamellar crack growth. 

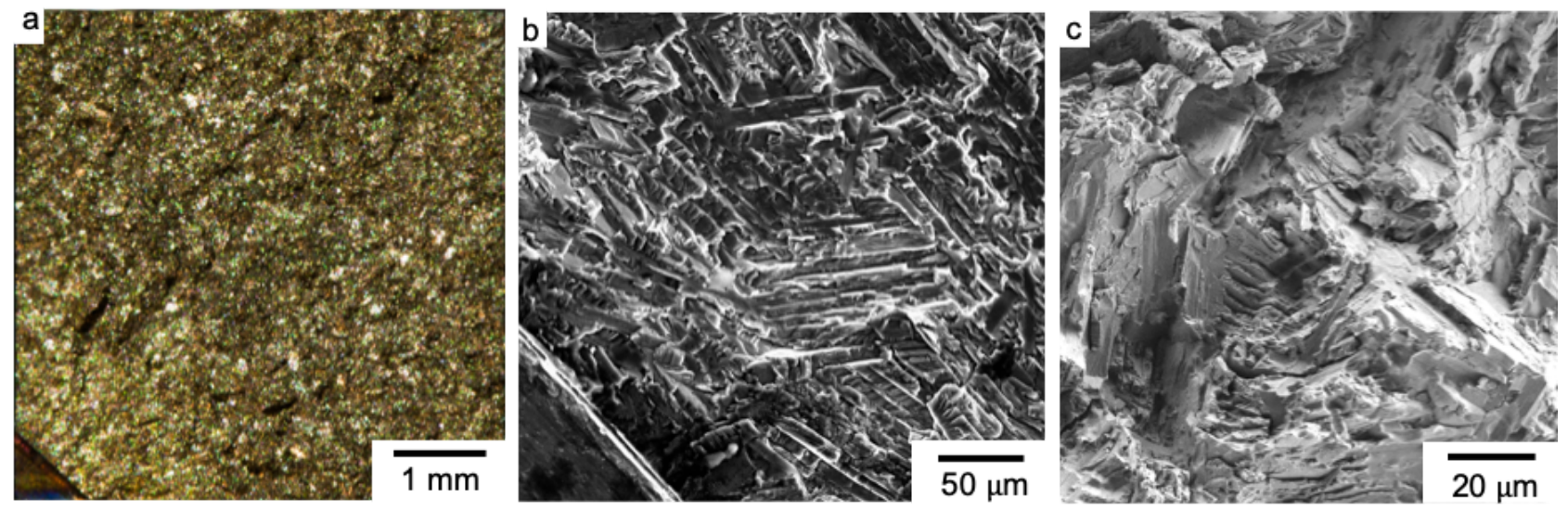

Figure 4: a) Fracture surface from a $0.5 \mathrm{~mm}$ notch at $400{ }^{\circ} \mathrm{C}$, b) translamellar crack growth in near-notch crack growth, c) inter- and intra-lamellar crack growth towards final specimen failure.
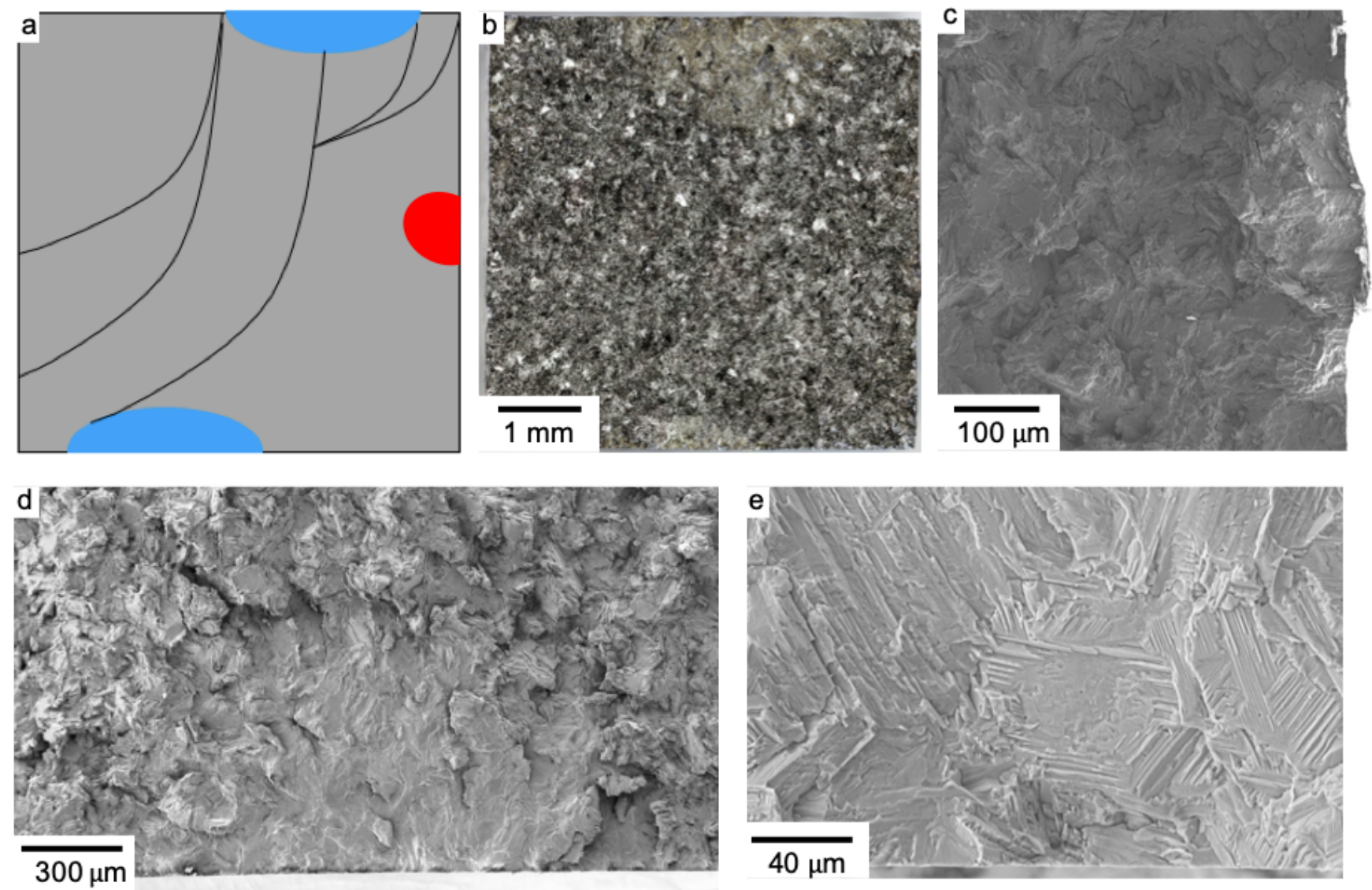

Figure 5: a) Schematic of the fracture surface of the specimen with a $0.06 \mathrm{~mm}$ machined notch with blue marking regions showing the initiation locations, and black lines marking river lines. The red area indicated a location where a large colony was observed to be pulled out. b) Optical micrograph of the $5 \times 5 \mathrm{~mm}$ fracture surface, c) large grain pulled out on the fracture surface shown in red on the schematic, d) region of fatigue shown on fracture surface, e) intiation region with trans-lamellar crack growth. (c-e) Secondary electron images.

The schematic in Figure 5a shows the features of the fracture surface of the specimen with a $0.06 \mathrm{~mm}$ diamond blade machined notch, with the fracture surface shown in Figure 5b. The fracture surface initiated in multiple locations away from the machined notch. A rougher overload region could be observed centrally, with large grains being pulled out due to the large plastic zone, shown in red in the schematic, and in Figure 5c. Two flatter regions were observed on the fracture surface, at the top and bottom of the Figure 5a, shown as blue. This indicates two initiation sites accompanied by trans-lamellar crack growth. The top fatigue region of initial crack growth can be seen to minimally increase in roughness throughout the fatigue away from an initiation site, and then change abruptly to a rougher cracking appearance, Figure $5 \mathrm{~d}$. Within the region of fatigue and trans-lamellar crack growth, the reduction of roughness can be traced back to find the area of initiation, Figure 5e. River marks down the fracture surface on each colony could also be 
traced, showing the direction of crack growth away from the top region of fatigue and trans-lamellar crack growth. Initiation occurred from a flat planar feature of similar composition, presumably associated with a colony with its face normal along the loading direction.

The specimen with the $0.03 \mathrm{~mm}$ FIB-machined notch initiated naturally from the central region of the gauge, but away from the notch, Figure 6a. The fracture surface, Figure 6b, shows fewer features than that of the sample with the 0.06 $\mathrm{mm}$ notch. However, a flatter region indicating fatigue could be observed at the bottom central side of the fracture surface, Figure 6c. The roughness in this could be traced back to find an area of initiation. Initiation was seen to correlate with borides sitting at prior- $\beta$ grain boundaries.

Conclusions

Fatigue crack initiation and growth at $400{ }^{\circ} \mathrm{C}$ in air was studied in a cast and HIP $\gamma$-TiAl alloy containing fine scriptlike borides for grain boundary control. The following observations were made:

1. For specimens with a notch smaller than the size of a colony, $\sim 100 \mu \mathrm{m}$, microstructural initiation was found to dominate. In some specimens, this could be correlated with the occurrence of borides; this might be due to the borides themselves or the orientation of the underlying colony.

2. Specimens with notches larger than the colony size initiated from the notch, and notch size was not found to have an effect on the fatigue crack growth threshold of $\sim 4 \mathrm{MPa} \sqrt{\mathrm{m}}$. Any effect of load on the fatigue crack propagation effect appeared to me small.

3. Fracture surfaces of $\gamma$-TiAl can be qualitatively analysed to determine if in overload, fatigue or in the initiation zone, based on optical profilometry of surface roughness and careful observation during electron microscopy.
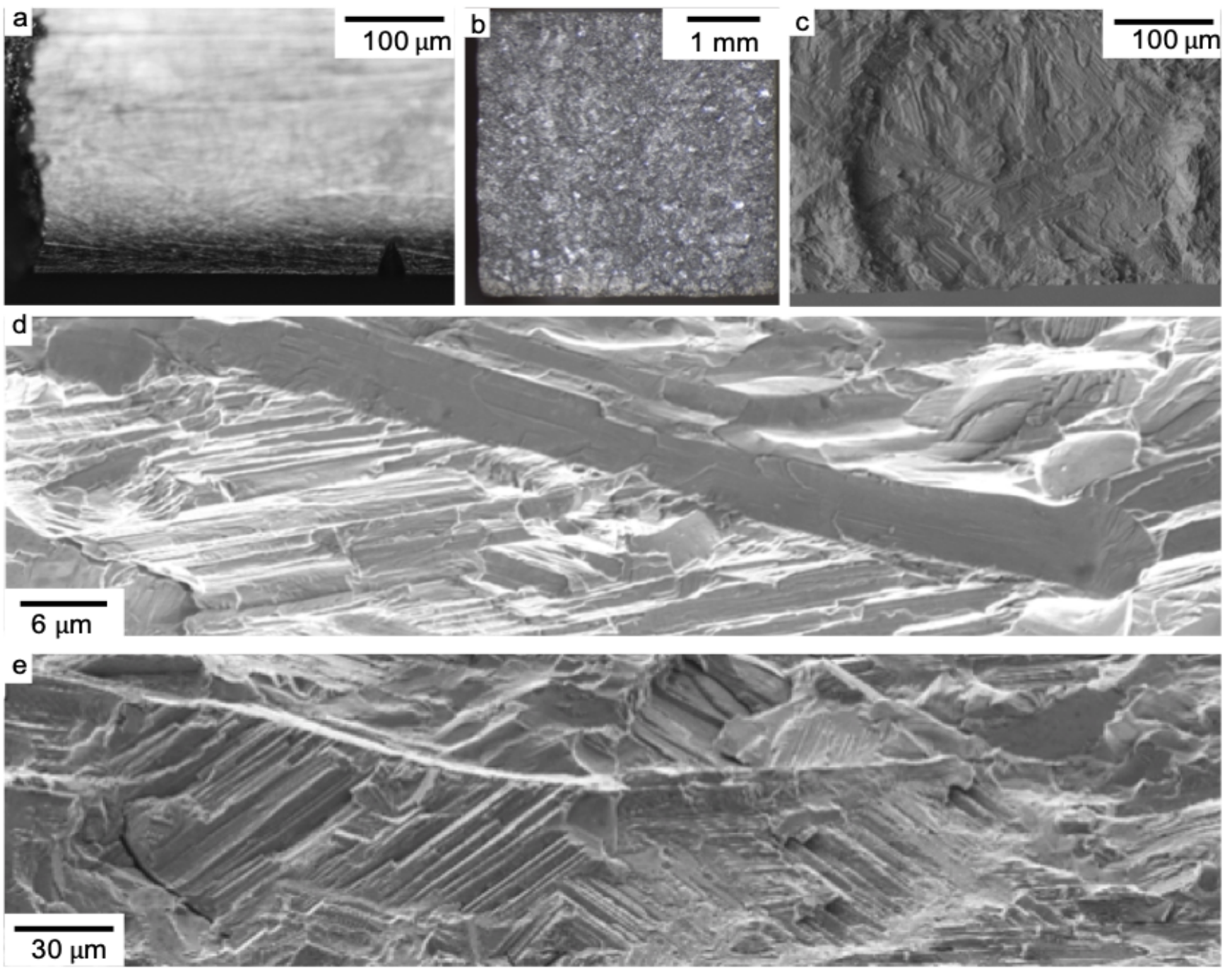

Figure 6: a) $0.03 \mathrm{~mm}$ notch in the central gauge was not the initiation site for the specimen. b) Optical micrograph of the $5 \mathrm{x} 5 \mathrm{~mm}$ fracture surface, c) region of fatigue shown on fracture surface, d) Boride ribbon found in the initiation region at zero tilt, e) and at $45^{\circ}$ tilt. (c-e) Secondary electron images. 


\section{References}

[1] H. Clemens, S. Mayer, Advanced Engineering Materials, (2013) 15(4), 191-215.

[2] G. Lutjering, J. C. Williams, Titanium, Springer, 2003.

[3] S. Suresh, Fatigue of Materials, Cambridge, 1991.

[4] M.S. Dahar, S.M. Seifi, B.P. Bewlay, J.J. Lewandowski, Intermetallics (2015) 57, 73.

[5] V. Bauer, H. J. Christ, Intermetallics, (2009) 17(5), 370-377.

[6] D.M Dimiduk, Materials Science and Engineering A, (1999) 263(2), 281-288

[7] T. Edwards, Beyond Ni based superalloys, Plasticity of Gamma Titanium Aluminide (2016).

[8] T. Christman, S. Suresh, Engineering Fracture Mechanics, (1986) 23(6), 953-964.

[9] R. Pippan, H. P. Stüwe, K. Golos, Fatigue, (1994) 16, 579-582. 